\title{
A Taxonomy of Massive Open Online Courses
}

\author{
Olga Pilli \\ Girne American University, North Cyprus \\ Wilfried Admiraal \\ Leiden University, The Netherlands
}

\begin{abstract}
Massive Open Online Courses (MOOCs) as a new approach to distance education, which originated from the open education resources (OER) movement, are becoming widespread throughout the world. Over time, early versions of cMOOCs have undergone changes in terms of use, name and structure. In their short life, MOOCs have been categorized into different taxonomies depending on, for example, their types, pedagogies, orientations, target participants, resources and content. This article proposes a new taxonomy to position MOOCs on two dimensions: massiveness and openness, which brings a fresh perspective for understanding varieties of MOOCs based on the two definitional elements. The dimensions of massiveness and openness are identified and discussed. Based on these, we conclude two dimensional matrix with four categories: (i) small scale and less open, (ii) small scale and more open, (iii) large scale and less open, (iv) large scale and more open. This classification provides a comprehensive description of different types of MOOCs which could be helpful to answer the necessities of MOOC providers, educators, students, and researchers.
\end{abstract}

Keywords: Massive open online courses; MOOCs; Open learning; Distance education; Online courses; Taxonomy of MOOCs

\section{Introduction}

The University of Chicago launched the first distance learning program in 1982 (Miller, 2014). As of the 1990s, however, a plethora of educational organizations have started offering online courses. One recent development in the field of distance education is Massive Open Online Courses (MOOCs), which offer free education for the masses. The first known MOOC was created by Massachusetts Institute of Technology (MIT) OpenCourseWare in 2002 to provide free web access to MIT course materials. Currently, MOOC platforms are shared by respected universities that provide open learning materials by utilizing cloud computing systems: Stanford's Coursera (www.coursera.org), founded by Andrew Ng and Daphne Koller, and Harvard and MIT's edX (www.edx.org), founded by Anant Agarwal (Maringe \& Sing, 2014). Additionally, Udacity (www.udacity.org), Udemy (www.udemy.com) and Australian MOOEC (piersim.com/mooec) have been offering open online courses since 2012 (Wilson \& Gruzd, 2014). Currently, there are more than 80 platforms that offer MOOCs, cooperating with the world's leading universities, leading scholars and industry experts in all areas.

MOOCs are online courses in which anyone, anywhere can participate, usually for free. They are made up of short video lectures combined with assignments, computer-graded tests and online 
discussion forums (Hoy, 2014). These massive courses typically share some common features: open access using the Internet, free of charge, asynchronous, interactive user forums and the opportunity to receive a certificate (McDonald \& Zlomek, 2014). MOOCs are built on the idea that "information is everywhere", extending access to education. MOOCs are courses but also support open, distributed, participatory and lifelong networked learning. The underlying idea of a MOOC is accessibility since anyone can participate and collaborate either to acquire new knowledge or to expand existing knowledge. This implies that MOOCs have the potential to create a pathway for life-long learning processes in the future (Seta, Kukulska-Hulme \& Arrigo, 2014).

MOOCs have been praised for bringing the educational opportunities of elite institutions to a wider audience, and for addressing the issue of increasing costs of higher education. However, MOOCS also have been criticized for their varying quality and low completion rates since the completion rate for many courses is less than $15 \%$, and for the limited amount of research on their effectiveness to promote learning (Stark \& Pope, 2014). Moreover, Kalman (2014) criticized MOOCs for not providing high-quality online learning systems compared to those offered by most distance education institutions. These shortcomings of MOOCs can negatively affect public attitudes towards distance education. MOOCs, he claims, do not pose the threat to traditional higher education providers that many have claimed because they cannot deliver what students (and employers) want from higher education. However, MOOCs, with their huge classes, variable cost minimization and low completion rates, may threaten to generate negative attitudes toward high-quality distance education providers. In fact, a UK government report on MOOCs stated that "The MOOC format itself suffers from weaknesses around access, content, quality of learning, accreditation, pedagogy, poor engagement of weaker learners, exclusion of learners without specific networking skills" (Bell, 2010, p. 4).

From a distance education point of view, some researchers do not see the further significance of massive open online courses in online learning since there are still unsolved issues that damage their reputations such as high-drop-out rates, weak assessment methods, and accreditation. Reports and research studies have indicated high enrolments rates and attributed it to multifarious advantages and possibilities for students to gain new skills and knowledge through life-long and self-directed learning experiences. However, the same sources also highlight low retention rates of these courses (Jansen \& Schuwer, 2015; Kleiman, Wolf, \& Frye, 2015). Apart from the high dropout rates, MOOCs are also criticized by some bodies of researchers for their less credibly evaluation strategies employing to assess the students' learning outcomes (Admiraal, Huisman, \& Pilli, 2015). For instance, peer-assessment and selfassessment are two commonly used evaluation methods to cope with the disadvantages due to the extraordinary number of students, but they are considered not sufficient to grade students in order to get recognized credits in most of the universities. Although numerous types of MOOCs are listed in the MOOC providers' web sites, the origin of this new phenomenon has been based on the connectivist theory. Therefore, the first MOOCs are considered cMOOCs that rooted in the connectivism. Despite known limited empirical output the real potential of MOOCs, unlike traditional online education programs, they present some advantages to the learners such as high-quality courses, high-quality digital learning materials and instructors who have worldwide reputation from prestigious universities (Dillahunt, Wang, \& Teasley, 2014). With all those advantages listed above MOOCs are standing in a promising position in higher education institutions.

As MOOCs have developed, debates around their real functions and formats have persisted (Literat, 2015) and classifications according to various dimensions have been proposed based on 
the evolution of MOOC platforms and conceptualizations (Koutropoulos \& Zaharias, 2015; Rosselle, Caron, \& Hautte, 2014).

The earliest, most well-known categorizations see MOOCs developed as either courses with an emphasis on connectivist ideas (cMOOCs) with students learning from and with both educators and each other in online course environments or as courses involving more individual-focused learning (xMOOCs) following traditional cognitivist-behaviorist approaches, with traditional course structure, content and methods (Seyedmonir, 2013).

Later, Reich (2012) established three categories based on orientation of the MOOCs according to profit, openness and learning, which resulted in MOOCs as (a) market-oriented, (b) openresource oriented, or (c) Dewey theory oriented. Similarly, Lane (2012) differentiated MOOCs into three types: network-based, task-based and content-based. Clark (2014) clustered MOOCs into eight different taxonomies based on learning functionalities: transferMOOCs, madeMOOCs, synchMOOCs, asynchMOOCs, adaptiveMOOCs, groupMOOCs, connectivistMOOCs and miniMOOCs.

More recently, Conole (2013) developed a classification schema for MOOCs based on twelve dimensions that can be used to define MOOC design and to evaluate MOOCs: degree of openness, scale of participation (massification) amount of multimedia use, amount of communication, extent to which collaboration is included, type of learner pathways (from learner-centered and less structured to teacher-centered and highly structured), level of quality assurance, extent to which reflection is encouraged, level of assessment, how informal or formal learning is addressed, participants' autonomy and diversity.

The necessity of developing new taxonomies for MOOCs is inevitable as diversity in types and structures emerges. Taxonomies help communicate about MOOCs adequately and clearly, as well as having practical value - they help shape appropriate design principles for better learning experiences. Furthermore, classification of MOOCs is important because it allows both students and educators to identify, group, properly name and describe the nature of them via a standardized taxonomy. Using taxonomy provides understanding the interrelationship among different types of MOOCs. In this taxonomy, we develop a new categorization to better define the distinctions between different types of MOOCs along the two basic dimensions of massiveness and openness. This taxonomy provides a framework to design and implement MOOCs in an educationally sound way, which also supports the further development of these types of courses. Therefore, this article aims to present a new taxonomy in light of the established types and structures of MOOCs.

\section{Two Dimensions of MOOCs: Massiveness and Openness}

This section is devoted to the two distinctive elements of MOOCs: massiveness and openness. In online education, massiveness regularly serves as a synonym for the concept of scale while openness describes a course with no barriers to participation with regards to time, place, pace, adaptivity, accessibility and costs. Clark (2014) has defined several dimensions of openness relevant to MOOCs: open access, open structure, open educational resources, open collaboration, open accreditation, open source code and open data. Similarly, Gilliot, Garlatti, Rebai, and Belen-Sapia (2013) classified MOOCs based on the degree of openness but from the participants' point of view: openness of learning goals, resources selection, organization of learning activities, organization of group work and collaboration. Furthermore, Sanchez-Gordon 
and Luján-Mora (2014) clustered openness of MOOCs into three meanings. Firstly, open for enrolment of students both on-campus as well as off-campus, with no prerequisites to enroll. Secondly, open course content and resources, without any time or money constraints. Thirdly, open technology and/or platform on which the course is offered.

As Stewart (2013) stated thousands of learners could be able to reach new digital literacies and to take new roles because of the MOOCs' particular combination of massiveness and openness. It is believed that open format and massive participations may have important consequences for education from a social communications and learning-focused perspective (Glance, Forsey \& Riley, 2013).

Practically, any MOOC can be defined in terms of massiveness (i.e., number of participants) and openness (i.e., degree of accessibility and flexibility). In this review, we categorize MOOCs into four classes based on these two dimensions: (I) small scale and less open, (II) small scale and more open, (III) large scale and less open, (IV) large scale and more open. Figure 1 represents this two-dimensional model for MOOCs.

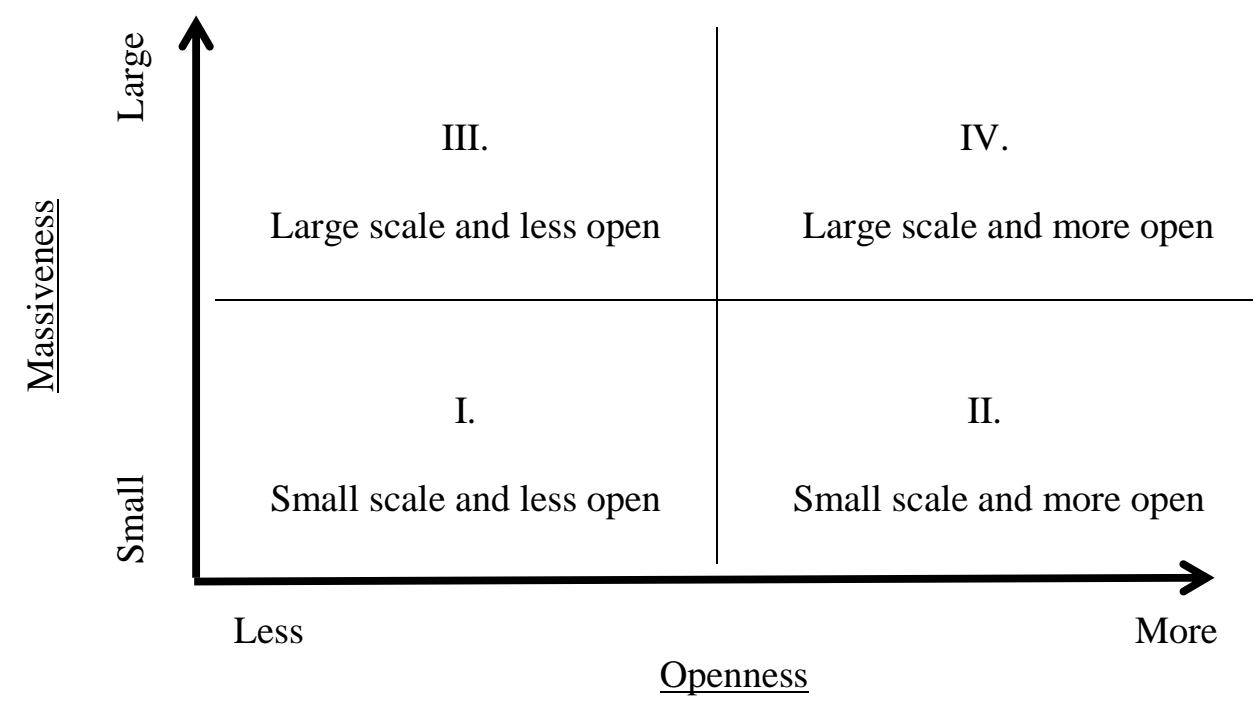

Figure 1. Two-dimensional Model for MOOC Taxonomy

The first quadrant is related to the small scale and less open MOOCs; number of participants are some respect limited (i.e. 200-500 participants instead of thousands). In this quadrant, openness of context is also limited for example because a fee is needed to access some parts of the course. This quadrant also includes forms of MOOCs that are used in regular distance or campus-based higher education. The second quadrant which is small scale and more open. The context is considered to be open, for instance because course materials and/or exams are free to all participants. In this quadrant, the $\mathrm{MOOC}$ forms are positioned that link to the original connectivist ideas of MOOCs. Large scale and less open MOOCS replaced in third quadrant which allow limitless participation with restricted content for free. In this quadrant, traditional distance higher education courses are positioned. The remaining quadrant, quadrant four, is associated with limitless participation and context. This quadrant refers to probably the most well-known MOOCs in which institutional experts express their knowledge and ideas through videos and course content. 


\section{Small Scale and Less Open MOOCs}

MOOCs characterized by a small number of participants and less open content are typical, traditional online courses. Sometimes, additional features include a course also being open to a limited number of off-campus users or that some parts of the course content (e.g. lecture notes or videos) are freely available. The well-known representative examples are SPOC, groupMOOC and task-based MOOCs.

\section{SPOCs}

Small Private Online Courses (SPOCS) are more similar to a flipped classroom than to a MOOC. This format was recently pioneered by Harvard and Yale on the edX platform. A SPOC uses video lectures, online resources and even MOOC-style assessments in a normal college course. In SPOCs, a small group of students collaborate (online or face-to-face) with teachers. So far, the SPOCs on edX have been open to a limited number (500) of outside participants, who compete for a place in the class by writing an admissions essay (Naidu, 2013). Selecting students based on the personal experiences shared in their essays allows instructors more insight regarding their students such that instructors are better equipped to tailor learner supervision to the learners' needs. At the end of the SPOC, learners can obtain a diploma. An example is the master course Sharia in the West offered by Prof. Dr. Maurits Berger from Leiden University to 25 oncampus students and 25 international online students selected based on their motivation and background. This 12-week SPOC addresses several manifestations of Sharia in the West including dress code, family law and Islamic finance.

\section{groupMOOC}

In this type of $\mathrm{MOOC}$, the focus is on small group collaborations to decrease dropout rates. The structure is basically closed and institutionally oriented, with a limited number of participants. Participants are selected by software that takes into account participants' sociodemographic and geographical background, skills and knowledge. Participants have a mentor to reinforce their commitment and progress. A typical example of a groupMOOCs is the NovoEd platform (Clark, 2014).

\section{Task-based MOOCs}

Task-based MOOCs emphasize skills in the sense that they ask the learner to complete particular tasks. In Jim Groom's ds106 at UMW, learning tasks are distributed and the formats are variable. There are many options for completing each assignment but a certain number and a particular variety of assignments need to be done to demonstrate the required skills. The community plays a crucial role, particularly to provide examples and assistance. Pedagogy of task-based MOOCs tends to be a mix of instructivism and constructivism to generate better learning outcomes. Therefore, using traditional approaches for assessment might be problematic in these MOOCs since these approaches contradict the underlying assumptions of task-based MOOCs (Lane, 2012). 


\section{Small Scale and More Open MOOCs}

The MOOCs in this category are provided by open source tools and participants are encouraged to share their learning outputs by using Creative Commons licenses, which allow learners to keep the copyright to their work but also allow others to copy, distribute and use their work non-commercially while ensuring that licensors get credit for their work (Creative Commons, 2016). A highly-open, online small MOOC is likely to be conducted via learning networks and social media tools, affording students real learning autonomy with guidance from an instructor as an option. Under this dimension of MOOC taxonomy, cMOOCs, BOOCs, COOCs, DOCCs, POOCs, LOOCs, gMOOCs, pMOOCs, adaptive MOOCs and network-based MOOCs can be listed.

\section{cMOOCs}

Connectivist MOOCs (cMOOCs) are based on connectivism as a theory of learning that emphasizes "creation", "creativity", "autonomy" and "social networked learning" (Siemens, 2012). cMOOCs are directed by explicit principles of connectivism, autonomy, diversity, openness and interactivity (Bell, 2010). They are commonly hosted by using free social networking sites (e.g., Facebook, Twitter, G +), LMS (Moodle) and student-created videos and exercises, wikis and blogs (Rodriguez, 2013). Learner-centered, distributive and connectivist approaches are the basics of cMOOCs. Knowledge is shared between participants via studentstudent interaction, student-content interaction and student-instructor interaction. While students are creators and contributors through blog posts, tweets, or discussion forums, the 'teacher' role is defined as a co-learner who is responsible for creating content and shaping goals by collaborating with other learners. There is no formal assessment, but informal feedback from knowledgeable participants serves an evaluation purpose. One of the main principles of Siemens (2005)'s connectivist learning approach emphasizes the learner's flexibility in navigating web sites with meaningful interaction and engagement. Kop (2011, p. 20) Identified four learningenhancing types of activities in cMOOCs: (1) aggregation (access to lots of content resources), (2) relation (reflection on the aggregated content through blogging, discussion boards and related social software) (3) creation (assignments for participants to create new ideas), and (4) sharing (of created content with other participants). Downes (as cited in Bates, 2014, para. 8) has acknowledged four significant design principles for cMOOCs: (a) learners' autonomy, (b) learners' diversity, (c) interactivity, and (d) openness. PLENK2010 (Personal Learning Environments, Networks, and Knowledge), CCK 08, 09, 11 (Connectivism and Connective Knowledge), MobiMOOC 2010 (Mobile Learning) and EduMOOC (ONLINE Learning today and tomorrow courses) are the main examples of cMOOCs (Ebben \& Murphy, 2014; Kop, 2011; Rodriguez, 2012).

\section{BOOCs}

A Big Open Online Course (BOOC) is a MOOC that is open to only a limited number of students, but offers advantages similar to those of a MOOC. It is expected to have more interaction since the number of participants is limited to a maximum of 500 participants. The design of BOOCs focuses on students' Wikifolios, informal reflections on the WikiFolios, the use of formal ondemand assessments and Digital Badges. A typical example of a BOOC is the free online course on educational assessment offered by the Indiana University School of Education (Hickey, Kelley, \& Shen, 2014). 


\section{coOCs}

Community Open Online Courses (COOCs) are small-scale, non-profit courses that corporations open online to provide courses for customers and/or employees. These communities are interested in a particular subject, and mostly engage in self-directed learning (Sanchez-Gordon \& Luján-Mora, 2014). COOCs can also appear under the name Corporate MOOC, which are intended for company employees and potential candidates, or more broadly to all business partners including suppliers, customers and prospects (Fitzgerald, 2013).

\section{DOCCs}

FemTechNet has presented Distributed Online Collaborative Courses (DOCCs) as an alternative to MOOCs. They are oriented toward collaborative, institutional activities in which each institution organizes a course around core learning resources. For instance, a DOCC on Feminist Dialogues on Technology uses a distributed pedagogical approach that allows many contributors-professors at various institutions including Yale University; Pennsylvania State University; Goldsmiths, University of London; and Flinders University in Australia, guest lecturers and the students themselves - to exchange ideas. Anne Balsamo, co-facilitator of the DOCC and Dean of the School of Media Studies at The New School indicated that DOCCs do not deliver a centralized singular syllabus to all the participants; it instead is organized around a central topic and based on deep feminist pedagogical commitments, which means that expertise is distributed among all participants and does not just reside with one or two individuals. DOCCs are different from traditional MOOCS in four ways (Meyer, 2012). First, they are not designed to make a profit. Second, they have taken the 'massive' out of the MOOC-DOCCS are designed for 20 students at most. Third, DOCCS are operationalized according to a feminist ideology that rejects the centralization of power. And fourth, DOCCS are a continuation of the pedagogy set into motion by the traditional MOOC, but are designed to meet the needs of those whose needs have not been addressed previously.

\section{POOCs}

Participatory Open Online Courses (POOCs) are aimed at creating participatory, rather than massive, courses that enable participants to engage with people inside as well as outside the program. All participants who register for a POOC are expected to participate actively by sharing, collaborating and creating knowledge using the POOC's digital platform. Two examples are JustPublics@365 Reassessing Inequality \& Reimagining the 21st Century: East Harlem Focus POOC and Media@McGill.

\section{LOOCs}

Unlike the massive courses, Little Open Online Courses (LOOCs) offer standardized assessments, grading and credits. Although participants include students who are registered to on-campus programs as well non-registered students from off-campus, the number of participants not registered to an on-campus program who are eligible to enroll is limited to five and participants who want to earn credit must be registered to an on-campus program. When taken for credit, LOOCs are payable up to six institutional credits. Moreover, LOOCs offer individual and on-time 
feedback provided by professors. All participants submit essays, participate in workshops and generally adhere to the same standards (Rosselle, Caron, \& Hautte, 2014). An example is Presque Isle's small-scale course offered by OpenU in which registered students can pay for up to six institutional credits via courses offered on the university campus.

\section{gMOOCs}

Game-Based and Game-Based Learning MOOCs (gMOOCs), proposed by Sherry Jones and Jack Park, follow connectivist and decentralized MOOC principles. Additionally, they use Digital Games for immersive learning. This is a new form of MOOC based on "play" and "interactivity" including video conversations, group problem solving, weekly digital games and exercises. In addition, synchronous chats are used on Tweetchat, GoogleHangout, Youtube, or Mightybell for question and answer sessions, as well as asynchronous discussions with creation and massive collaborative writing on Etherpads (Jones \& Singer, 2014). Advanced English Composition gMOOC is an example in which participants play a series of digital games, specifically narrativebased role-playing games (RPG), and analyze the rhetorical strategies used by the games to influence players' game decisions, ultimately leading gamers to experience certain game outcomes (Jones \& Caruso, 2013).

\section{pMOOCs}

The Project-Based MOOC (pMOOC) is a version of the MOOC that relies on the collective development of small innovative projects. Varieties are participative courses that aim at jointly creating knowledge within the framework of a particular project and small-size xMOOCs with connectivist design approaches (Mor, 2012). Such project-based MOOCs offer great potential for media education: the large number of participants makes it possible to address new issues and current media education problems, or to make extensive research on social media. An example of a pMOOC is the OLDSMOOC - Open Learning Design Studio's MOOC Learning Design for a 21st Century Curriculum (McAndrew, 2013).

\section{AdaptiveMOocs}

Many MOOCs are in a structure that follows a sequential and linear learning path, which might be insufficient to respond to participants' needs and preferences and can make students less responsive. This flat, linear and non-flexible nature of MOOCs could be changed into a structure that is more sensitive to personal history, needs and choices (Clark, 2013). With the use of software to personalize learning experiences (just what Google does for searching), adaptiveMOOCs provide tailored learning experiences based on dynamic assessment and data gathered during the course. Having conducted many experiments and studies on the application of adaptive learning in personalized online learning, the Center for Innovation and Excellence in eLearning of the College of Advancing and Continued Studies, University of Massachusetts Boston, Synaptic Global Learning developed the first adaptiveMOOC in the area of computational molecular dynamics (CMD), providing a strong pedagogical framework and a personalized learning experience in a MOOC learning environment. According to Sonwalkar (2013) adaptiveMOOCs have the potential to become the next revolution in online education since they use learning analytics to adapt learning environments according to personal preferences, which could be a solution for high dropout rates. 


\section{Network-based MOOCs}

The network-based MOOC is Lane (2012)'s first type of MOOC classification that is based on the element of network building. The intended goal, instead of knowledge and skill acquisition, is constructing knowledge through social conversations and experiencing a new way of learning with distributed, open web systems. The pedagogy of network-based MOOCs is based on connectivist-style methods. Resources are provided, but exploration is more important than mastering any particular content. Therefore, conducting a traditional assessment is difficult (Lane, 2012). An example is the graduate-level course EC\&I 831 Social Media and Open Education, offered in 2007 by Dr. Alec Couros of the University of Regina (Sanchez-Gordon \& Luján-Mora, 2014). This course was open to both students taking the course for university credits and other, non-credit students, who wanted to participate in a non-formal learning capacity.

\section{Large Scale and Less Open MOOCs}

Large scale and less open MOOCs often allow a limitless number of participants, with limited openness in terms of the target group of students, registration fees, course duration, customized content and course design, including assessment. The $\mathrm{VOOC}, \mathrm{SMOC}, \mathrm{HOOC}$, miniMOOC and POOC are examples.

\section{VOOCs}

Vocational Open Online Courses (VOOCs) are based on vocational pedagogies, where practical tasks and procedures can be shown in real world examples along with experts as 'talking heads' providing advice. Unlike MOOCs as long-term academic courses, VOOCs are targeted, bite-size vocational courses that are free at point of delivery and typically take around an hour to complete (Clark, 2014). The first vocational MOOC or VOOC, Citizens' Maths, opened up learning in functional maths funded by a partnership of four UK organizations, Calderdale College (a further education college in Halifax, West Yorkshire), CogBooks (an adaptive learning company), The Institute of Education (a center of excellence in research into maths education and into technology-enhanced learning) and OCR (a major UK awarding body that is part of Cambridge Assessment, the University's international exams group), with support from Google (Trust, 2014).

\section{SMOCs}

The Synchronous Massive Online Course (SMOOC or SynchMOOC) is an experiment currently being carried out in a University of Texas psychology course. Rather than having students actually attend class, professors broadcast their lectures live online for students to watch at home during designated class times. In SynchMOOCs, everyone follows the same class schedule and may even be required to log in at the same time, for example, to attend a webinar or a question-answer session with a keynote speaker. The description that was provided by The Wall Street Journal placed SMOOC "somewhere between a MOOC, a late night television show and a real-time research experiment where students, professors and teaching assistants [are required] 
to be online at the same time". Enrolment was open to anyone (up to 10,000 students) for a $\$ 550$ registration fee, and students who finish are eligible to earn three transferable credits. In many versions, SynchMOOCs have fixed start and end dates (Clark, 2014).

\section{HOOCs}

The Hybrid Open Online Course (HOOC) is a version of a flipped classroom, which is used to enhance collaboration between MOOC participants and on-campus students. In fall 2013 at the University of Pittsburgh, Gordon Mitchell, an associate professor of communication, offered a $\mathrm{HOOC}$ on the Greek Rhetorician Isocrates. In this HOOC, the graduate students on campus and the online participants were allowed to interact. The online students listened to the seminars and participated in the discussion by posting comments on Twitter. And each on-campus doctoral student enrolled in the HOOC was required to prepare a lesson and teach it to the online students. In this way, participant roles in HOOCs are co-located in individual and collective learning environments that allow for shared meanings and collective analyses. This form of online education could be used to enhance collaboration between online and classroom-based learners by providing self-managed discussions (Sacks \& Myers, 2014). Some have defined this combination as a blended learning format, and called it a Blended MOOC (BOOC).

\section{mini-MOOCs}

According to Clark (2013), some MOOCs cover less content and fewer skills, which only require hours or days instead of a semester or weeks as in regular MOOCs. Mini-MOOCs are short courses with only one or two clearly defined learning objectives (Nielson, 2013). The Open Badges movement tends to be more aligned with this type of MOOC. Another example is Nottingham's 2-week MOOC How to Read a Mind.

\section{POOCs}

Another alternative to MOOCs is the Personalized Open Online Course (POOC), which provides non-standardized education for the masses by customizing and adjusting the content to its users. With technology, learning can be personalized according to students' characteristics, preferences and activities. Thus, teaching materials, content, assessment and feedback can be formulated in parallel with the participants' cognitive scaffolding characteristics with the help of individualized learning paths (Sanchez-Gordon \& Luján-Mora, 2014; Zapata-Ros, 2013).

\section{Large Scale and More Open MOOCs}

A MOOC categorized as large scale (massive) and more open typically refers to the current breed of elite, hyper-centralized Coursera-style MOOCs. Although students can regulate the time and style of study, there is little flexibility in the course objectives, content, sequencing and assessment, which are determined prior to course commencement. Examples for this quadrant are $\mathrm{xMOOC}$, transfer $\mathrm{MOOC}$, madeMOOC, asynchMOOC, SPOC, Content-based MOOC, FlexMOOC, IMOOC, MOOC-Eds and MOOR. 


\section{xMOOCs}

xMOOCs are characterized by step-by-step learning that breaks down content into small stages, limits feedback and interaction, pre-determines office-hours for student questions and uses a criterion-referenced assessment approach (Ebben \& Murphy, 2014). xMOOcs provide a platform to repeatedly deliver content from instructors of top-ranked universities online, and they follow a course design model similar to most in-class higher education courses. The design of the courses, unlike cMOOCs, is based on linear, content-based learning paths. The underlying learning philosophy in $\mathrm{xMOOCs}$ is the cognitive-behaviorist school of thought. $\mathrm{XMOOCs}$ present the content of the course with a list of topics, readings and small lecture videos. Students are assessed through a combination of quizzes, assignments and final exams where the format of the exam is mostly short-answer or multiple choice questions. The most popular method of instruction is pre-recorded video lectures, which are typically 3 to 15 minutes long (Hew \& Cheung, 2014; Kop, Fournier, \& Mak, 2011). YouTube videos, website pages and sometimes live video conferences with professors are commonly used as additional instructional materials in $x M O O C s$. These modes of communication transmit information from the source to the receivers in a way that results in limited instructor-student interaction. Students are expected to follow instructions in a video-based format and to complete the assignments, quizzes and exams. Instructors act as the main authority responsible for creating the content, assignments, quizzes and exams. Peer-review according to pre-established rubrics is a common means of evaluating essay-type assignments. Lecture videos, text-based readings, slides, practice exercises, audio files, URLS to other resources and online articles are typical course materials in XMOOCs. Udacity's CS101 and Coursera's Artificial Intelligence are well-known examples of xMOOCs.

\section{transferMOOCs}

Transfer MOOCs lie at the "most traditional" end of the MOOC spectrum. These are courses designed for classroom delivery that have been put onto a MOOC platform. Many of the courses offered through Coursera belong to this category. These courses deliver content primarily through "talking head" videos and assigned readings, and they assess learning outcomes using online quizzes and tests. This type of MOOC would work best for training when the main goal is knowledge transfer, such as employee orientation and business etiquette training (Clark, 2013).

\section{madeMOOCs}

MadeMOOCs tend to be more innovative by making effective use of video and interactive material, avoiding talking heads in favor of Khan Academy or Udacity hand on board sequences. Clark (2013) states that madeMOOCs are courses originally designed as MOOCs rather than for classroom delivery. Their videos often feature whiteboard problem-solving sequences rather than talking heads. These courses have an interactive approach that goes beyond just knowledge transfer: students interact with the software by solving problems and receiving instant feedback. Time management, project management, financial training and courses involving individual training simulations lend themselves well to the madeMOOC format. The quality of material, production tasks, solving problems and experiences of interaction with the material and software, collaborative work and experiences of co-evaluation among students define the characteristics of madeMOOCs. Udacity used to offer these courses for focusing selfdirected learners who just want to watch the videos and solve the exercises, mainly in computer science classes. 


\section{asynchMOOCs}

The asynchMOOC courses are completely open, with no fixed start or end dates, and have elastic evaluation and course-task deadlines. Since it can start at any time and place, it is ideal for people with overloaded schedules and in cases where synchronous participation is difficult, such as for employees in different time zones (Clark, 2013). This flexibility may help reduce high dropout rates. Asynchronous MOOCs are entirely self-paced. Although corporate training has traditionally been done in a synchronous fashion, this trend is changing. Between 2006 and 2007 self-paced study jumped from $15 \%$ to $20 \%$ of all training hours, and that number is continuing to grow. AsynchMOOCs are available from Coursera completely in self-training mode, but then there is no guaranteed certificate of completion.

\section{SPOCs}

In the Self-Paced Online Course (SPOC) version of MOOC, students can work their way through the course following their own schedule, taking educational detours along the way if needed. Coursera offers self-paced courses intentionally designed to be taken by a wide diversity of trainees without relying on instructor feedback. SPOCs can be included in campus courses to benefit outside students. Since the courses provide a high degree of flexibility, participants can set their own tempo and choose which session they want to start. The initial enrolment period is about 12 weeks, and most courses require a proctored exam that is conducted and supervised off-campus. Participants are expected to be self-disciplined to be successful and complete the course (Muñoz-Merino, Ruipérez-Valiente, Alario-Hoyos, Pérez-Sanagustín, \& Delgado Kloos, 2015). An example of a SPOC is Udacity's Al course, which was offered in fall 2013.

\section{Content-based MOOCs}

Content-based MOOCs are those with a mass registration of students, taught by professors from major universities and using automatic evaluation methods. In this case it is difficult to create user-communities because users follow the course independently. The acquisition of content is more important than participation in networks. Thus, it often follows an instructionist teaching methodology. Both formative and summative evaluation can be used for assessment. An example is Lane (2012)'s content-based MOOCs with huge enrolment, commercial prospects, well-known professors from large universities, automated testing and exposure in the popular press. Unlike the connectivist MOOCs, which focus on networking or task completion, a huge number of learners focus mostly on content in these courses (Lane, 2012).

\section{Flex-MOOCs}

A flex-MOOC is a learner-centered $\mathrm{MOOC}$ that allows students to create learning paths aligned with their strengths, needs and preferences by selecting modules. Flex-MOOCs provide content in modules that allow learners to control the sequence and timeline of content presentation. This module-based MOOC is proposed by COIL (Centre for Online Innovation for Learning), Penn State. It is claimed that the flex-MOOC has some unique features related to its flexibility that not only help its sustainability but also make it distinct from other MOOCs. For instance, learners are free to select learning objectives, content, assignments and assessment mode within a 
provided set. Furthermore, students have the flexibility to arrange the time and level of assignments and assessment (Peck, 2013).

\section{iMOOCs}

Learner-centeredness, study flexibility, student interaction and digital inclusion are the main design principles of iMOOCs that are not common in other MOOC formats. Furthermore, these courses combine autonomous and self-directed learning with a strong social dimension, and articulate the essential flexibility for the learner along with the structure needed to help understand assignment. In iMOOCs, course content can be accessed by anyone, but registration is required. Learning is based on completing activities by creating artefacts (texts, videos, presentations, concept maps, etc.) that are published online and demonstrate participants' knowledge and skills in terms of course content (Gilliot et al.,2013; iMOOC Model, 2015). An example is the iMOOC Digital Skills for Teachers, which aims to spark reflection on and debate around developing skills for the use of digital technologies in education.

\section{MOOC-Eds}

The MOOC-Ed Initiative was developed by The Friday Institute, and courses are built in collaboration with a team of experts in instructional technology, mathematics education and literacy education (Kleiman, Wolf, \& Frye, 2015). Massive Online Open Courses for Educators, or MOOC-Eds, are professional development experiences that engage participants in new technology-enabled learning opportunities that are becoming widely used for both adults and students. MOOC-Ed courses include core resources and supplemental materials around a specific topic, while also allowing for a great deal of personalization and flexibility. Because there is not a fixed path or a fixed curriculum everyone has to follow, learning can be self-directed, peer-supported, case study and/or project-based. Indeed, participants can - and are expected to - navigate their own paths, consistent with their own goals and the needs of their school or district, while being supported and guided by the facilitators, resources, education experts and fellow participants. An example is Planning for the Digital Learning Transition in K-12 Schools, which has been offered twice by The Friday Institute.

\section{MOORs}

Massive Open Online Research (MOOR) is basically a MOOC with research as a main focus. Participants from around the world with different learning backgrounds and skills collaborate in research activities in a very practical way. The first MOOR, called Bioinformatics Algorithms, was offered by Pavel Pevzner of the University of San Diego's Jacob's School of Engineering in fall 2013 (Hosler, 2014). Coursera students in that MOOR had the opportunity to immediately put theory into practice and be mentored by top experts in the field. The MOOR format is a promising way to combine classroom learning and real-world research.

\section{Conclusion}

MOOC models and formats have been changing since connectivist MOOCs (cMOOCs) emerged in 2008. These changes are due to the advance of e-technologies and the positive outcomes 
achieved by MOOCs. The term "connectivist" MOOC was used to define pedagogical approaches with self-directed students collaborating with other students and instructors in networked learning environments (Rolfe, 2015). As the time passed, those initial cMOOCs changed into more deductive models: the xMOOCs. Since 2012, these free and mostly non-credentialed courses have attracted many universities and institutions of higher learning that believe these courses can polish their reputation for modernization and help them grow beyond their physical borders. Further changes have been induced by the need for more flexibility, which has led to the emergence of different types and formats of MOOCs.

This article proposed a new taxonomy for MOOCs along two distinctive dimensions: massiveness and openness. Based on these two dimensions MOOCs were classified into four different categories: (I) small scale and less open, (II) small scale and more open, (III) large scale and less open, (IV) large scale and more open. This taxonomy revealed that the most recently developed MOOCs fall under the small scale and more open quadrant. In addition, more profit-oriented rather than pedagogically-focused MOOCS are located in the large scale and less open quadrant. However, as Toven-Lindsey, Rhoads, \& Lozano (2015) indicate, identifying which pedagogical approach is prominent in each quadrant of the taxonomy is not possible. It is difficult to categorize an entire class of courses into just one of four categories (the objectivist-individual, objectivist-group, constructivist-individual, and constructivist-group) that provide teaching approach frameworks for online learning (Arbaugh \& Benbunan-Fich, 2006). In other words, it is not easy to categorize each quadrant with one pedagogical approach since the pedagogical tools used in each quadrant could differ from one course to another. Thus, it is essential to gain better understanding of the range of pedagogical tools used in each quadrant. The pedagogical tools, including content, teaching and learning activities, roles of teachers and students, and assessment could be identified and categorized in each quadrant of this taxonomy.

MOOCs, as the latest evolution phase of open education, have changed rapidly becoming more heterogeneous in terms of the types of courses provided as well as in providing more personalized learning environments. These developments correspond with the goals of higher education institutions. Although there are various approaches to classify MOOCs into different taxonomies (Rosselle, Caron, \& Hautte 2014; Sanchez-Gordon \& Luján-Mora, 2014), it is not certain which taxonomy is most practical and functional for stakeholders. For instance, what kind of MOOC would be the best choice for students with distinctive priorities and/or backgrounds? Similarly, it is good to know which MOOC format could be appropriate for particular course content and/or subject matter. Moreover, it is also valuable for MOOC providers and higher education institutions to know basic differences and functions of various types of MOOCs in order to develop MOOCs for different groups of students with different demands and backgrounds. Finally, it is important to emphasize that there is not one type of MOOC, but many different types with various pedagogical structures and degrees of openness and massiveness. Thus, MOOC consumers, providers and researchers should be aware of the distinctive features of MOOCs (i.e., openness and massiveness), which could lead to different choices, design principles and evaluations.

\section{References}

Admiraal, W., Huisman, B., \& Pilli, O. (2015). Assessment in massive open online courses. The Electronic Journal of e-Learning (EJEL), 13(4), 207-216. 
Arbaugh, J.B. \& Benbunan-Fich, R. (2006). An investigation of epistemological and social dimensions of teaching in online learning environments. Academy of Management Learning \& Education, 5, 435-447.

Bates, T. (2014). Comparing xMOOCs and cMOOCs: Philosophy and practice. Online Learning and Distance Education Resources. Retrieved on 8 June 2016 from http://www. tonybates.ca/2014/10/13/comparing-xmoocs-and-cmoocs-philosophy-and-practice/

Bell, F. (2010). Connectivism: Its place in theory-informed research and innovation in technology-enabled learning. The International Review of Research in Open and Distance Learning, 12(3), 98-118.

Clark, D. (2013). MOOCs: Taxonomy of 8 types of MOOC. Retrieved on 8 June 2016 from http://donaldclarkplanb.blogspot.co.uk/search?q=MOOCs:+taxonomy

Clark, D. (2014). MOOCs: Who's using MOOCs? 10 different target audiences. Retrieved on 8 June 2016 from http://donaldclarkplanb.blogspot.com.cy/2013/04/moocs-whos-usingmoocs-10-different.html

Conole, G. (2013). MOOCs as disruptive technologies: Strategies for enhancing the learner experience and quality of MOOCs. e-Lis. Retrieved on 8 June 2016 from http://eprints. rclis.org/19388/

Creative Commons (2016). Retrieved on 8 June 2016 from https://creativecommons.org/ licenses/

Dillahunt, T. R., Wang, B. Z., \& Teasley, S. (2014). Democratizing higher education: Exploring MOOC use among those who cannot afford a formal education. The International Review of Research in Open and Distance Learning, 15(5), 178-196.

Ebben, M. \& Murphy, J. S. (2014). Unpacking MOOC scholarly discourse: A review of nascent MOOC scholarship. Learning Media and Technology, 39(3), 328-345. doi: 10.1080/ 17439884.2013.878352

Fitzgerald, M. (2013). Rise of the corporate MOOC. Information Week. Retrieved on 8 June 2016 from http://www.informationweek.com/strategic-cio/team-building-andstaffing/rise-of-the-corporate-mooc/d/d-id/1112784

Gilliot, J.-M., Garlatti, S., Rebai, I., \& Belen-Sapia, M. (2013, May 28). The concept of iMOOC for mastered opening (French: Le concept de iMOOC pour une ouverture maîtrisée). Paper presented at the MOOC workshop at the EIAH'2013. Toulouse, France.

Glance, D. G., Forsey, M. \& Riley, M. (2013). The pedagogical foundations of massive open online courses. First Monday, 18(5-6). DOI:10.5210/fm.v18i5.4350

Hew, K. F. \& Cheung, W. S. (2014). Students' and instructors' use of massive open online courses (MOOCs): Motivations and challenges. Educational Research Review, 12, 45-58. doi: 10.1016/j.edurev.2014.05.001

Hickey, D. T., Kelley, T. A., \& Shen, X. (2014). Small to big before massive: Scaling up participatory learning analytics. Proceedings of the Fourth International Conference on Learning Analytics and Knowledge. Indianapolis, Indiana, USA.

Hosler, A. (2014). Massive open online research: The MOOC evolves into the MOOR. Retrieved on 8 June 2016 from http://www.emergingedtech.com/2014/01/massive-open-onlineresearch-the-mooc-evolves-into-the-moor/ 
Hoy, M. B. (2014). MOOCs 101: An Introduction to Massive Open Online Courses. Medical Reference Services Quarterly, 33(1), 85-91. doi: 10.1080/02763869.2014.866490

iMOOC Model. (2015) Retrieved on 8 June 2016 from http://imooc.uab.pt/model_en

Jansen, D. \& Schuwer, R. (2015). Institutional MOOC strategies in Europe. Retrieved on 8 June 2016 from http://www.eadtu.eu/documents/Publications/OEenM/Institutional_MOOC _s trategies_in_Europe.pdf

Jones, S. \& Caruso, K. (2013, July). gMOOC and rgMOOC: Theory and design. Paper presented at the e-Learning Consortium of Colorado. Denver, Colorado.

Jones, S. \& Singer, D. (2014, March). Composition on a new scale: game studies and massive open online composition. Paper presented at the Conference on College Composition and Communication (CCCC). Indianapolis, Indiana.

Kalman, Y. M. (2014). A race to the bottom: MOOCs and higher education business models. Open Learning, 29(1), 5-14. doi: 10.1080/02680513.2014.922410

Kleiman, G., Wolf, M. A., \& Frye, D. (2015). Educating educators: designing MOOCs for professional learning. In P. Kim (Ed.), The MOOC revolution: massive open online courses and the future of education (pp. 117-146). New York and London: Routledge.

Kop, R. (2011). The challenges to connectivist learning on open online networks: Learning experiences during a massive open online course. The International Review of Research in Open and Distance Learning: Special Issue on Connectivism: Design and Delivery of Social Networked Learning, 12(3). Retrieved on 8 June 2016 from http://nparc.cistiicist.nrc-cnrc.gc.ca/npsi/ctrl?action=rtdoc\&an=18150443

Kop, R., Fournier, H., \& Mak, J. S.F. (2011). A pedagogy of abundance or a pedagogy to support human beings? Participant support on massive open online courses. International Review of Research in Open and Distance Learning, Special Issue - Emergent Learning, Connections, Design for Learning, 12(7), 74-93.

Koutropoulos, A. \& Zaharias, P. (2015). Down the rabbit hole: An initial typology of issues around the development of MOOCs. Current Issues in Emerging eLearning 2(1): Article 4

Lane, L. (2012). Three kinds of MOOCs. Lisa's teaching blog. Retrieved on 8 June 2016 from http://lisahistory.net/wordpress/2012/08/three-kinds-of-moocs/

Literat, I. (2015). Implications of massive open online courses for higher education: Mitigating or reifying educational inequities? Higher Education Research \& Development, 34(6), 1164-1177. doi: 10.1080/07294360.2015.1024624

Maringe, F. \& Sing, N. (2014). Teaching large classes in an increasingly internationalising higher education environment: pedagogical, quality and equity issues. Higher Education, 67(6), 761-782. doi: 10.1007/s10734-013-9710-0

McAndrew, P. (2013). Learning from open design: Running a learning design MOOC. eLearning Papers, 33, 1-4.

McDonald, M. \& Zlomek, E. (2014). What's a MOOC? QuickTake. Retrieved on 8 June 2016 from http://www.bloombergview.com/quicktake/whats-a-mooc

Meyer, R. (2012). What it's like to teach a MOOC (and what the heck's a MOOC?). Retrieved on 8 June 2016 from http://tinyurl.com/cdfvvqy. 
Miller, G. (2014). History of distance learning. Retrieved on 8 June 2016 from http://www.worldwidelearn.com/education-articles/history-of-distance-learning.html

Mor, Y. (2012). pMOOC pedagogical pattern. Retrieved on 8 June 2016 from http://www.olds. ac.uk/blog/pmoocpedagogicalpattern

Muñoz-Merino, P. J., Ruipérez-Valiente, J. A., Alario-Hoyos, C., Pérez-Sanagustín, M., \& Delgado Kloos, C. (2015). Precise effectiveness strategy for analyzing the effectiveness of students with educational resources and activities in MOOCs. Computers in Human Behavior, 47, 108-118. doi: http://dx.doi.org/10.1016/j.chb.2014.10.003

Naidu, S. (2013). Transforming MOOCs and MOORFAPs into MOOLOs. Distance Education, 34(3), 253-255. doi: 10.1080/01587919.2013.842524

Nielson, B. (2013). What type of MOOC is right for you? Retrieved on 8 June 2016 from http://www.yourtrainingedge.com/what-type-of-mooc-is-right-for-you/

Peck, K. (2013). "flex-MOOCs" - An inevitable step in the evolution of online learning. Retrieved on 8 June 2016 from http://coil.psu.edu/blog/flex-moocs/

Reich, J. (2012). Summarizing all MOOCs in one slide: Market, open and Dewey. EdTech Researcher Retrieved on 8 June 2016 from Education Week website: http://blogs. edweek.org/edweek/edtechresearcher/2012/05/all_moocs_explained_market_open_a nd_dewey.html

Rodriguez, C. O. (2013). Two distinct course formats in the delivery of connectivist MOOCs. Turkish Online Distance Education, 14(2), 66-80.

Rodriguez, O. (2012). MOOCs and the Al-Stanford like courses: Two successful and distinct course formats for massive open online courses. The European Journal of Open, Distance and E-Learning 2012/II, 1-13.

Rolfe, V. (2015). A systematic review of the socio-ethical aspects of massive open online courses. European Journal of Open, Distance and e-Learning, 18(1), 53-72.

Rosselle, M., Caron, P.-A., \& Hautte, J. (2014). A typology and dimensions of a description framework for MOOCs. Paper presented at the European MOOCs Stakeholders Summit 2014 - eMOOCs 2014. Lausanne, France.

Sacks, R. \& Myers, R. (2014). Teaching in the open: Widening access or homogenizing learning opportunities? International HETL Review, 4(2). Retrieved on 8 June 2016 from https://www.hetl.org/teaching-in-the-open-widening-access-or-homogenizing-learningopportunities/

Sanchez-Gordon, S., \& Luján-Mora, S. (2014, March). MOOCs gone wild. Paper presented at the the 8th International Technology, Education and Development Conference. Valencia, Spain.

Seyedmonir, B. (2013). The one world school house: Education reimagined. Distance Education, 34(3), 399-405. doi: 10.1080/01587919.2013.835777

Siemens, G. (2005). Connectivism: A learning theory for the digital age. Journal of Instructional Technology and Distance Learning, 2(1), 3-10.

Siemens, G. (2012). MOOCs are really a platform. Retrieved on 8 June 2016 from http://www.elearnspace.org/blog/2012/07/25/moocs-are-really-a-platform/ 
Sonwalkar, N. (2013). The first adaptive MOOC: A case study on pedagogy framework and scalable cloud architecture-Part I. MOOCs Forum, 1(P), 22-29. doi: 10.1089/mooc. 2013.0007

Stark, C. M. \& Pope, J. (2014). Massive open online courses: How registered dieticians use MOOCs for nutrition education. Journal of the Academy of Nutrition and Dietetics, 114(8), 1147-1155. doi: http://dx.doi.org/10.1016/j.jand.2014.04.001

Stewart, B. (2013). Massiveness + openness = New literacies of participation? MERLOT Journal of Online Learning and Teaching, 9(2). Retrieved on 8 June 2016 from http://jolt.merlot. org/vol9no2/stewart_bonnie_0613.htm

Toven-Lindsey, B., Rhoads, R. A., \& Lozano, J. B. (2015). Virtually unlimited classrooms: Pedagogical practices in massive open online courses. The Internet and Higher Education, 24, 1-12. doi: 10.1016/j.iheduc.2014.07.001

Trust, U. C. (2014). Citizen maths. Retrieved on 8 June 2016 from http://www.ufi.co.uk/ projects/citizen-maths

Wilson, L. \& Gruzd, A. (2014). MOOCs - International information and education phenomenon? Bulletin of the American Society for Information Science and Technology, 4O(5), 35-40. doi: 10.1002/bult.2014.1720400510

Zapata-Ros, M. (2013). POOC. Open network. Retrieved on 8 June 2016 from http://redesabiertas.blogspot.com.cy/2013/07/pooc.html

Correspondence: Olga Pilli, Assistant Professor, Faculty of Education, Girne American University, Girne, North Cyprus 